Article

\title{
Estimation of Extreme Significant Wave Height in the Northwest Pacific Using Satellite Altimeter Data Focused on Typhoons (1992-2016)
}

\author{
Hye-Jin Woo ${ }^{1}$ (D) and Kyung-Ae Park ${ }^{1,2, *(D)}$ \\ 1 Department of Earth Science Education, Seoul National University, Seoul 08826, Korea; hyejinwoo@snu.ac.kr \\ 2 Research Institute of Oceanography, Seoul National University, Seoul 08826, Korea \\ * Correspondence: kapark@snu.ac.kr; Tel.: +82-02-880-7780
}

Citation: Woo, H.-J.; Park, K.-A. Estimation of Extreme Significant Wave Height in the Northwest Pacific Using Satellite Altimeter Data Focused on Typhoons (1992-2016). Remote Sens. 2021, 13, 1063. https:// doi.org/10.3390/rs13061063

Academic Editor: Vladimir

N. Kudryavtsev

Received: 1 February 2021

Accepted: 9 March 2021

Published: 11 March 2021

Publisher's Note: MDPI stays neutral with regard to jurisdictional claims in published maps and institutional affiliations.

Copyright: (c) 2021 by the authors. Licensee MDPI, Basel, Switzerland. This article is an open access article distributed under the terms and conditions of the Creative Commons Attribution (CC BY) license (https:/ / creativecommons.org/licenses/by/ $4.0 /)$.

\begin{abstract}
The estimation of extreme ocean wave heights is important for understanding the ocean's response to long-term changes in the ocean environment and for the effective coastal management of potential disasters in coastal areas. In order to estimate extreme wave height values in the Northwest Pacific Ocean, a 100-year return period were calculated by applying a Peak over Threshold (PoT) method to satellite altimeter SWH data from 1992 to 2016. Satellite altimeter SWH data were validated using in situ measurements from the Ieodo Ocean Research Station (IORS) south of Korea and the Donghae buoy of the Korea Meteorological Administration (KMA) off the eastern coast of Korea. The spatial distribution and seasonal variations of the estimated 100-year return period SWHs in the Northwest Pacific Ocean were presented. To quantitatively analyze the suitability of the PoT method in the Northwest Pacific, where typhoons frequently occur, the estimated 100-year return period SWHs were compared by classifying the regions as containing negligible or significant typhoon effects. Seasonal variations of extreme SWHs within the upper limit of $0.1 \%$ and the PoT-based extreme SWHs indicated the effect of typhoons on the high SWHs in the East China Sea and the southern part of the Northwest Pacific during summer and fall. In addition, this study discusses the limitations of satellite altimeter SWH data in the estimation of 100-year extreme SWHs.
\end{abstract}

Keywords: satellite altimeter; significant wave height (SWH); extreme SWH; Peak over Threshold (PoT) method; typhoon; Ieodo Ocean Research Station (IORS)

\section{Introduction}

Tropical cyclones are accompanied by heavy rainfall, unusually high waves and strong winds, all of which have a great impact on the coastal environment. The intensity of tropical cyclones or the frequency of the most intense cyclones has increased as an effect of climate change [1,2]. The intensity of tropical cyclones is increasing locally as a result of the changes in the cyclones' trajectories and the location of the maximum intensity [3-5]. The extreme significant wave height (SWH) is increasing globally as well as regionally, especially in coastal regions [6-10]. Increases in extreme wave height caused by tropical cyclones and hazardous events, combined with predicted sea-level rises (e.g., [11-13]), have the potential to increase the magnitude of disasters along with coastal erosion. Therefore, it is very important to estimate the extreme wave height, such as the 100-year return period SWH, as well as to understand the wave variability over decades.

The long-term return period values of wave height, 100-year return period SWHs, are intuitively determinable if the SWHs have been measured for a sufficiently long period over 100 years. However, the temporal duration of most SWH measurements is shorter than the expected return period. Therefore, several methods for estimating extreme values by applying extreme value analysis (EVA) such as the Initial Distribution Method (IDM), Annual Maximum (AM) method, and Peaks over Threshold (PoT) method have been developed over the past few decades (e.g., [14-17]). Studies have estimated the extreme 
wave height in the global ocean and regional seas by applying these statistical methods to buoy measurements and shipborne wave recorder data [7,18-23], satellite observation data [24-30], or model simulation data [31-35].

It is important to develop sophisticated statistical techniques for estimating extreme wave heights and to understand their spatio-temporal distribution in the global ocean and regional sea. In addition, it is also important to study the applicability and limitations of various estimation techniques that have been developed and utilized in previous studies. In particular, it is valuable to verify that long-term return period SWHs is adequately estimated in seas where extreme events such as typhoons frequently affect the estimation of extreme wave height.

The Northwest Pacific has a variety of ocean and atmospheric phenomena that cause the spatial and temporal variability of SWH, as shown in the long-term mean of satellite SWH data from 1992 to 2016 (Figure 1a,b). Previous studies have reported an increasing trend for SHW as well as extreme SWH values corresponding to the upper $1 \%$ in the Northwest Pacific (e.g., [36]). In addition, as shown in Figure 1c,d, the Northwest Pacific is a region with one of the highest frequencies of high-intensity tropical cyclones [37]. On average, more than 28 tropical cyclones occur per year [38], and the frequency of tropical cyclones accounts for $30 \%$ of the total global tropical cyclones [39]. Therefore, the Northwest Pacific is very suitable for the estimation of the 100-year return period SWH because of the relative abundance of extreme events such as tropical cyclones. Thus, it is important to understand the characteristics of extreme wave height in regions affected by tropical cyclones. Although the spatial distribution of the 100-year return period of SWH in the Northwest Pacific region has been presented [40,41], few studies have been conducted on the effect of tropical cyclones on extreme SWH.
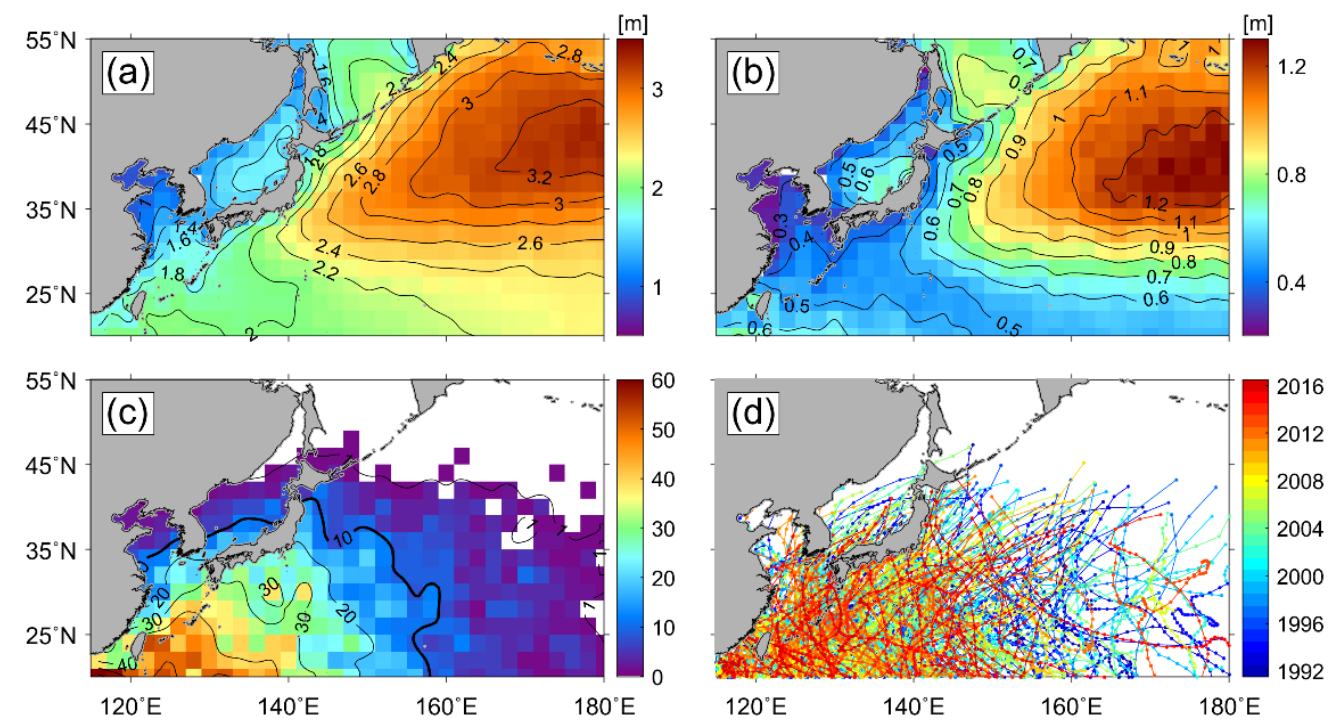

Figure 1. Spatial distribution of (a) the annual mean and (b) standard deviation of significant wave height (m), (c) the number of typhoons in each bin, and (d) the typhoon tracks from 1992 to 2016 in the Northwest Pacific, where the colors denote the years 1992 to 2016.

The objective of this study is to investigate and verify the extreme wave heights using satellite altimeter-observed data in the Northwest Pacific, where typhoons and extratropical storms occur frequently. This is achieved by (1) validating the satellite altimeter data using in situ measurements; (2) applying the EVA scheme commonly used to estimate the extreme wave heights; (3) comparing the estimated extreme wave heights with the maximum SWH measurements; and (4) investigating the difference in extreme wave height characteristics between typhoon region and non-typhoon region in the Northwest Pacific. This study also aims to discuss the limitations and precautions for estimating the extreme wave height 
using satellite altimeter data and to demonstrate the necessity of in situ data to verify the satellite-derived extreme wave heights.

\section{Data and Methods}

\subsection{Satellite Data}

In this study, the altimeter SWH data provided by Institut Français de Recherche pour l'Exploitation de la Mer (IFREMER) from January 1992 to December 2016 (25 years) were utilized [42]. This database is composed of nine altimeters (European Remote Sensing-1 (ERS-1), Topography Experiment/Poseidon (TOPEX/Poseidon), European Remote Sensing-2 (ERS-2), Geosat Follow-On (GFO), Joint Altimetry Satellite Oceanography Network-1 (Jason-1), Environmental Satellite (Envisat), Joint Altimetry Satellite Oceanography Network-2 (Jason-2), Cryosat-2, and Satellite for Argos and Altika (SARAL)) data over the study period, as shown in Table 1. The altimeter SWH data used in this study were quality controlled with along-track data. In addition, to improve accuracy and consistency, corrections of each altimeter SWH data were also performed by Queffeulou and Croizé-Fillon [42] by the comparison of satellite data with in situ measurements or an intercomparison between altimeter data. In the Northwest Pacific, these altimeter SWH data were validated to be about $0.1 \mathrm{~m}$ in terms of bias and $0.3 \mathrm{~m}$ in terms of the root-mean-square error (RMSE) [36].

Table 1. Information on satellite altimeters used in this study, including the operational period, data period, and repeat period.

\begin{tabular}{cccc}
\hline Satellite & Operational Period & Data Period & Repeat Period (Days) \\
\hline ERS-1 & 17 July 1991-10 March 2000 & 2 January 1992-2 June 1996 & $3,35,168$ \\
\hline TOPEX/Poseidon & 10 August 1992-9 October 2005 & 25 September 1992-8 October 2005 & 9.9156 \\
\hline ERS-2 & 21 April 1995-5 September 2011 & 15 May 1995-2 July 2011 & 35 \\
\hline GFO & 10 February 1998-22 October 2008 & 7 January 2000-7 September 2008 & 17 \\
\hline Jason-1 & 7 December 2001-21 June 2013 & 15 January 2002-20 June 2013 & 9.9156 \\
\hline Envisat & 1 March 2002-8 April 2012 & 14 May 2002-8 April 2012 & 35 \\
\hline Jason-2 & 20 June 2008-9 October 2019 & 4 July 2008-31 December 2016 & 9.9156 \\
\hline Cryosat-2 & 8 April 2010-Present & 16 July 2010-31 December 2016 & 30 \\
\hline SARAL & 25 February 2013-Present & 14 March 2013-31 December 2016 & 35 \\
\hline
\end{tabular}

To investigate if satellite SWH data could be measured near the typhoon center under a condition of severe sea states, we used $10.8 \mu \mathrm{m}$ channel infrared images of the Communication, Ocean, and Meteorological Satellite/Meteorological Imager (COMS/MI) for a period from 26 to 27 August 2012. During this period, serval satellite altimeter tracks passed over the typhoon Bolaven in the seas around the Korean Peninsula, and satellite SWHs could be obtained for the typhoon event.

\subsection{In-Situ Data}

The Ieodo Ocean Research Station (IORS), located at $125.18^{\circ} \mathrm{E}, 32.12^{\circ} \mathrm{N}$ in the East China Sea and south of the Korean Peninsula, has been operating since 2003 [43]. It was constructed on an underwater rock with a depth of approximately $40 \mathrm{~m}$. It is far from land or islands, approximately $149 \mathrm{~km}$ southwest of Marado, Korea, $276 \mathrm{~km}$ from the west of Dorisima, Japan and $287 \mathrm{~km}$ from the nearest island of China, as shown in Figure $2 \mathrm{~b}$. The SWH measurements from IORS were used from 2005 to 2016 to evaluate the accuracy of the altimeter SWH data in regions with the greatest frequency of extreme conditions such as typhoons. The tracks of satellite altimeters around IORS are presented in Figure 2c-k, which contains all the regular tracks and transitional tracks during the study period from 1992 to 2016. 

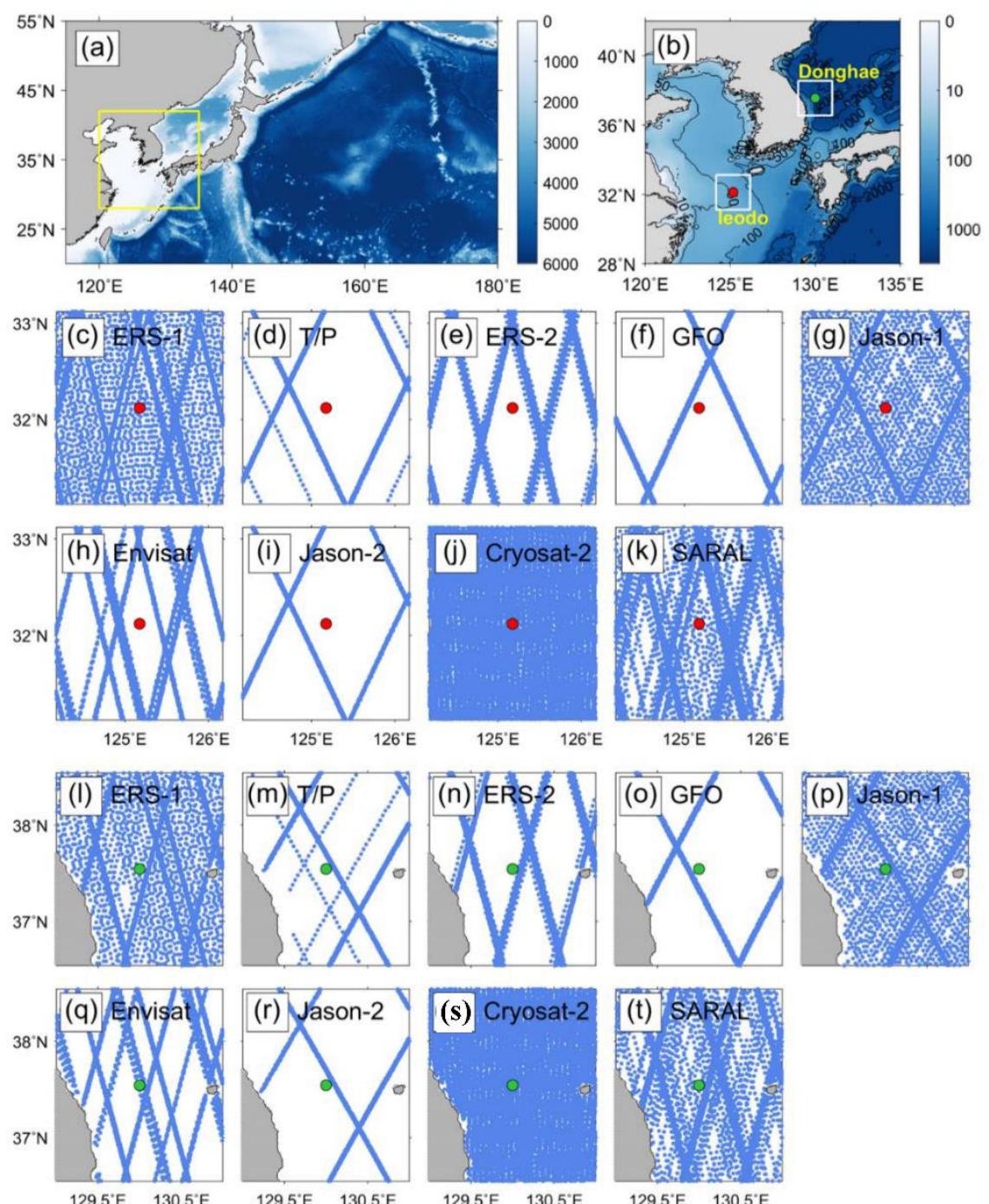

Figure 2. (a) Bathymetry (m) in the Northwest Pacific; (b) an enlarged map corresponding to the yellow box of (a), showing the locations of Ieodo Ocean Research Station (IORS) $\left(125.18^{\circ} \mathrm{E}, 32.12^{\circ} \mathrm{N}\right)$ and Donghae buoy $\left(129.95^{\circ} \mathrm{E}, 37.54^{\circ} \mathrm{N}\right)$. $(\mathbf{c}-\mathbf{k})$ Satellite altimeter tracks around IORS marked with a red circle, and (1-t) tracks around the Donghae buoy, marked with a green circle.

As IORS is a tower, the wave heights are observed using a radar instrument on a platform-based remote sensing system, in contrast to the conventional buoy using an accelerometer to measure the wave height. The observed SWH data might contain abnormal values due to various atmospheric and marine environments and instrumental errors. The Korea Hydrographic and Oceanographic Agency, which distributes the observation data from IORS, has developed a series of quality control procedures for wave height measurements based on the techniques presented by the Intergovernmental Oceanographic Commission [44,45] and Evans et al. [46]. The agency distributes the SWH data from IORS with quality control information. In this study, quality controlled data at 1-h interval with quality flags were used for analysis.

In addition, the SWH measurements from the Donghae buoy of the Korea Meteorological Administration (KMA) were utilized. The buoy is located relatively far from the coast $\left(129.95^{\circ} \mathrm{E}, 37.54^{\circ} \mathrm{N}\right)$, in an area with less influence from typhoons than IORS. The data were collected from 2011 to 2016. The SWH measurements at 1-h interval from Donghae buoy were also quality controlled by applying quality flags provided with the data.

As shown in Figure 3a, SWHs higher than $8 \mathrm{~m}$ were observed at IORS. The monthly average is a mixture of seasonal variation in which the SWH increases in winter and 
decreases in summer, and the highest SWH in August due to frequent passage of typhoons (Figure 3c,e). The SWHs from Donghae buoy show more pronounced seasonal variability than those of IORS (Figure 3d,f), but they also exhibit high values exceeding $4.5 \mathrm{~m}$ due to typhoons in August-September. Another difference from the SWH measurements from IORS is that there is a peak in April. This is related to the fast-developed low-pressure passing through the East Sea (Sea of Japan) $[47,48]$.
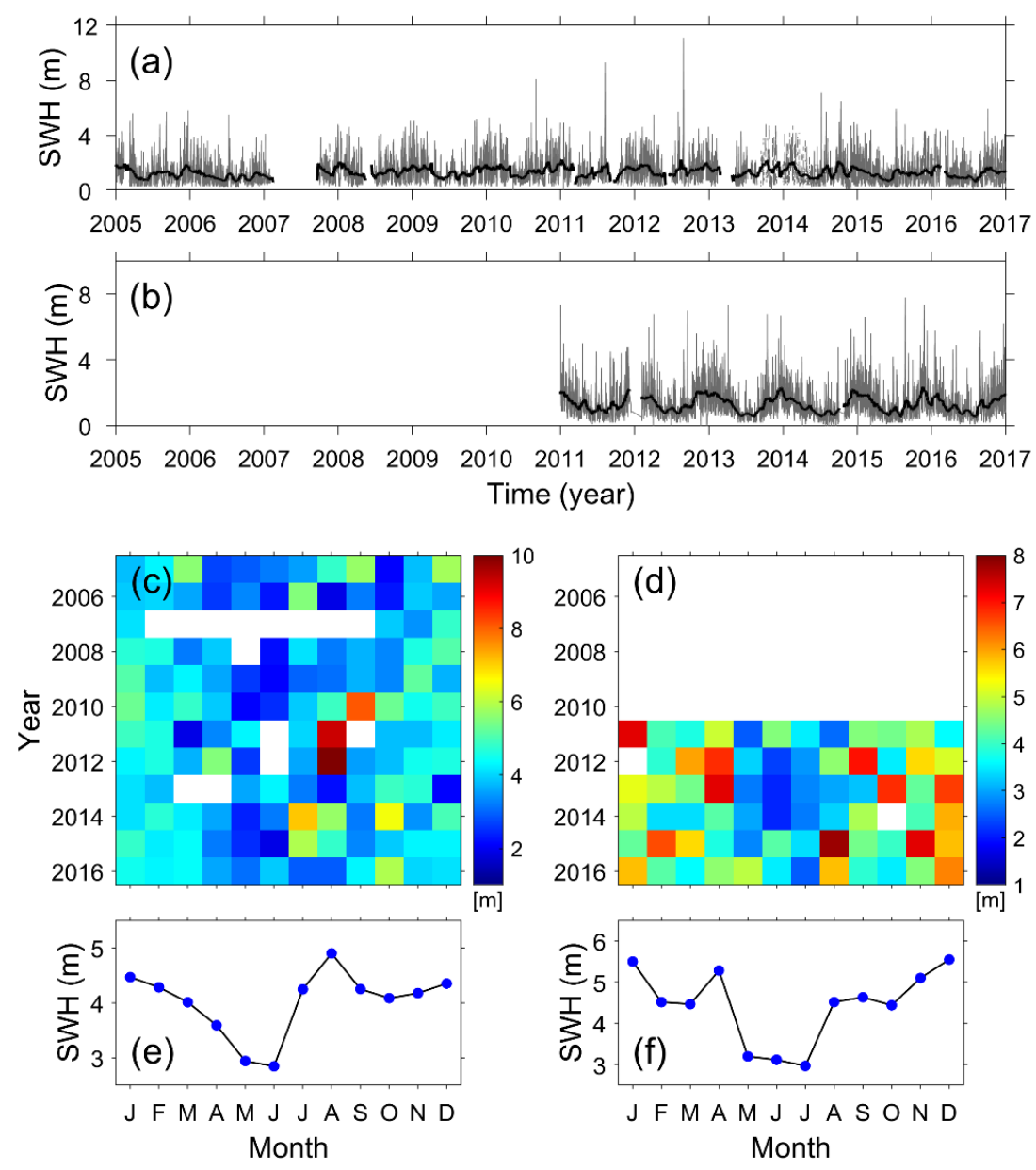

Figure 3. Time series of the significant wave height (SWH) measurements from (a) the IORS and (b) the Donghae buoy, year-month plots of SWH (m) from (c) the IORS and (d) the Donghae buoy, and monthly average of SWHs from (e) the IORS and (f) the Donghae buoy.

\subsection{Best Track Data of Typhoons}

Information regarding the occurrence and movement of typhoons from 1992 to 2016 in the study area was obtained from the International Best Track Archive for Climate Stewardship (IBTrACS) version 3 release 10 (v03r10) [49]. The number of typhoons during the study period was calculated in bins of $2^{\circ} \times 2^{\circ}$ and used as an index to evaluate whether extreme conditions such as typhoons were sufficiently represented in the EVA results.

\subsection{Estimation of Extreme Value}

In order to understand the spatial distribution of the extreme wave height using the EVA in the Northwest Pacific, SWH data measured along satellite altimeter tracks were sub-sampled within a bin of $2^{\circ} \times 2^{\circ}[24,28,50]$. In this study, the PoT method was utilized to estimate extreme SWHs using buoy measurements and satellite altimeter data (Figure 4). The PoT method, which uses data exceeding a defined threshold, alleviates the limitations of the AM method while maintaining data as being independent and identically distributed. 
The data greater than the threshold follow a generalized Pareto distribution (GPD) in the EVA [17]:

$$
G(z)=1-\left[1+\xi\left(\frac{z-\mu}{\sigma}\right)\right]^{-1 / \xi}
$$

where $\mu$ is the location parameter, $\sigma$ is the scale parameter, and $\xi$ is the shape parameter. As the threshold $\mu$ is a factor that affects the result of EVA, it is of considerable importance to select an appropriate threshold value. Too low a threshold causes the estimated extreme value to have a low bias, while too high a threshold does not maintain stability because of excessive suppression of the amount of data $[17,21]$. Therefore, the stability of parameters should be tested. The parameters were estimated for every value of the threshold [17]. For the selection of the threshold, the shape parameter $(\xi)$ and modified scale parameter $\left(\sigma^{*}=\sigma-\xi \mu\right)$ were presented in Figure 5 . Based on the results of the stability test, the 99.5th percentile SWH suggested by Méndez et al. [21] was selected among the various threshold values proposed in previous studies $[21,24,25,28]$.

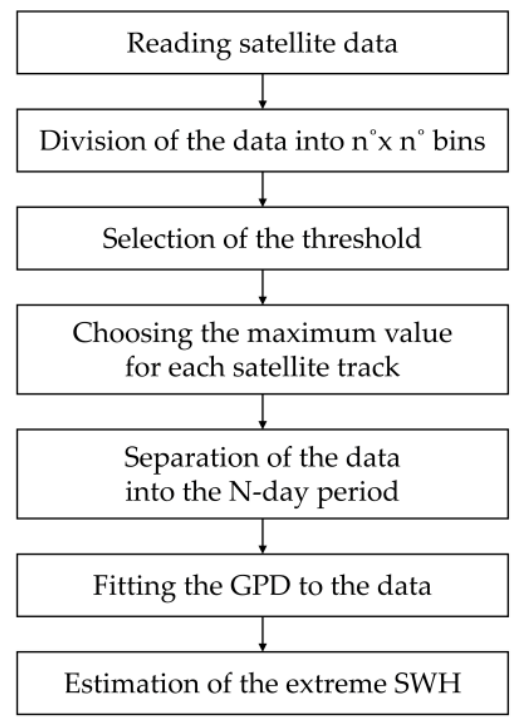

Figure 4. Flowchart of estimation of extreme SWH using Peak over Threshold analysis with a generalized Pareto distribution, where $\mathrm{n}$ and $\mathrm{N}$ represent the 2 degree and 3 days, respectively.
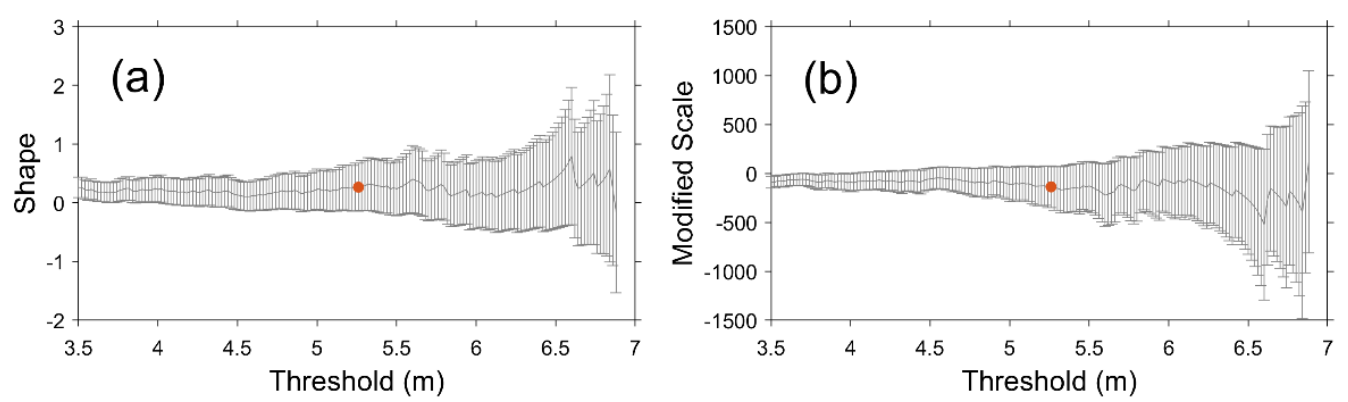

Figure 5. (a) Shape parameter $(\xi)$ and (b) modified scale parameters $\left(\sigma^{*}=\sigma-\xi \mu\right)$ with $95 \%$ confidence intervals for every value of threshold. The red dot indicates the 99.5 th percentile $\mathrm{SWH}$.

To perform the PoT analysis, it was hypothesized that the data should satisfy the precondition of independence between the data. However, a satellite altimeter along the track would be likely to observe similar SWH values within a bin, which may violate the precondition. Taking this into account, we selected one maximum value for each track of the satellite within a given bin. Nevertheless, other satellites were likely to undermine this independence by observing similar SWHs within a given spatial range. 
As such, an additional constraint was given to use a temporal range for the selection of only one maximum value among the previously selected maximums. Previous studies have mentioned that the independence of data could be ensured by separating these data into specific time intervals such as two days [35,51] or three days [21]. In this study, data separated at three-day time intervals were used for the EVA.

In the PoT method, the probability level for the 100-year return period SWH is determined as follows:

$$
P\left(H_{S}<H_{S}{ }^{100}\right)=1-\frac{N_{Y}}{100 N_{\text {PoT }}},
$$

where $N_{\text {PoT }}$ is the number of exceedances used in the PoT analysis, and $N_{Y}$ is the number of years covered by the analysis. As mentioned above, the PoT method complements the defects of the annual maximum method, but also has a limitation in that this method shows an extreme dependency on the threshold, and variations of the estimated extreme value were amplified if insufficient data were available for this approach.

\section{Results}

\subsection{Validation of Satellite SWH Data}

The altimeter SWH data were validated by comparison with the SWH measurements from the IORS and Donghae buoy prior to the estimation of the extreme SWH value. Figure $6 \mathrm{a}, \mathrm{b}$ present a comparison between the altimeter $\mathrm{SWH}$ data and the in situ measurements at the IORS and the Donghae buoy. When the collocation procedure between altimeter along-track SWH data and in situ measurements was performed using the criteria of $30 \mathrm{~min}$ and $50 \mathrm{~km}$ in time and space, the numbers of the matchup data produced at the IORS and Donghae buoy were 833 and 556, respectively. The SWH data from the altimeters were in good agreement with both SWH measurements from IORS and Donghae buoy. The comparison resulted in RMSE of $0.38 \mathrm{~m}$ at the IORS and $0.23 \mathrm{~m}$ at Donghae buoy, respectively. Compared with the SWH measurement from IORS, it was noted that there was a tendency for the altimeter SWH data to be slightly overestimated with a positive bias error of $0.23 \mathrm{~m}$. This tendency was found to be due to a mixture of errors caused by the characteristics of the IORS platform, which observes the wave height using a microwave instrument at a height of $35 \mathrm{~m}$ in addition to satellites [52]. In contrast, the altimeter SWH data showed an insignificant bias of $0.01 \mathrm{~m}$ in comparison with the measurements from the Donghae buoy.

The IORS and the Donghae buoy measure SWH data with a high temporal resolution of approximately $1 \mathrm{~h}$ at a point location, while the altimeter data are sparsely distributed with different temporal differences. Therefore, the SWH data may differ from each other depending on these observation characteristics. Considering the differences, monthly averaged values and the maximum values of the SWHs were calculated for both in situ measurements and satellite data. In the case of altimeter SWH data, the mean and maximum values were calculated using along-track data within a bin of $2^{\circ} \times 2^{\circ}$ based on the location of the IORS and the Donghae buoy. Figure $6 c-f$ indicates the comparisons of the monthly means of wave heights from the in situ observation stations and satellite observations. Overall, both the average and maximum SWHs observed from satellites and point stations were in good agreement for the entire period. Two large peaks of more than $10 \mathrm{~m}$ in the monthly maximum (Figure 6d) were generated by the typhoons Muifa and Bolaven, which passed over the IORS in August 2011 and August 2012, respectively. Similar values were measured for both the IORS and the altimeter. However, the maximum SWH obtained from the IORS showed a peak in August 2010 when Kompasu passed, while the maximum SWH from the altimeter did not show these characteristics. When comparing the monthly maximum SWH observed from Donghae buoy and altimeters, some peaks measured in the Donghae buoy did not appear in the altimeter observations (Figure 6f). This suggests that the altimeters failed to observe the extreme waves generated by storms that occurred suddenly in the East Sea (Sea of Japan). This is related to the fast movement of the typhoons at a relatively high speed and the fast-developed low-pressure $[47,48]$. 

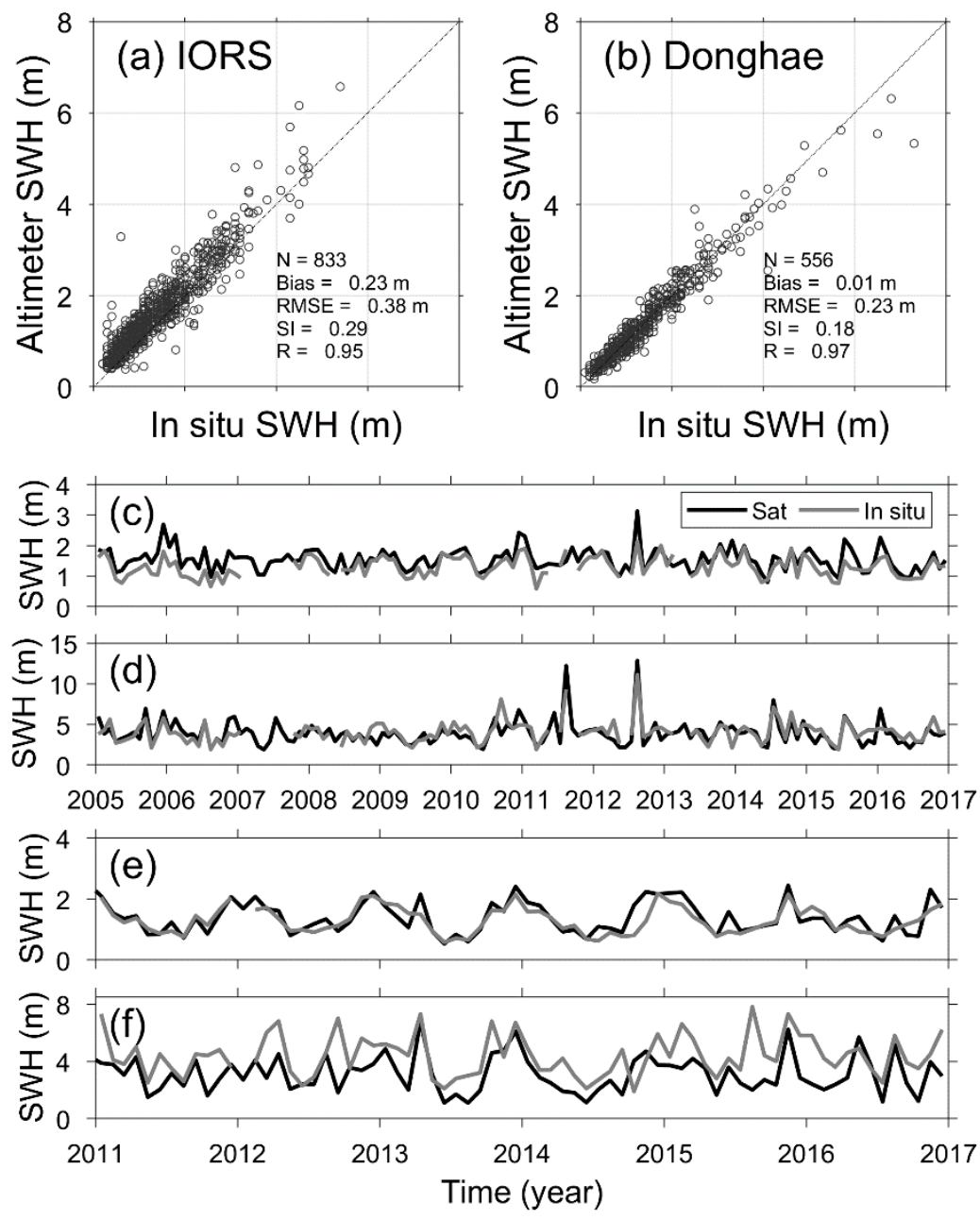

Figure 6. Comparison between altimeter-observed SWH and in situ measurements from (a) the IORS and (b) the Donghae buoy; time series of (c) monthly mean SWH, (d) monthly maximum SWH at the IORS, (e) monthly mean SWH, and (f) monthly maximum SWH at the Donghae buoy, within a bin of $2^{\circ} \times 2^{\circ}$ including the in situ measurement stations.

\subsection{Estimation of Extreme SWH Using PoT Method}

Figure 7 shows the results of extreme SWH estimates by applying the PoT method using the GPD to the satellite observed SWH data from the sea surrounding in situ measurement stations of the IORS and the Donghae buoy. The small plot on the upper right side of each figure presents a comparison between the quantile of the observed data and the quantile of the PoT estimated value of altimeter-observed SWH data from the seas surrounding the IORS and Donghae buoy. Since relatively high SWH data were selected by excluding the SWHs smaller than the threshold value, as shown in red curves of Figure 7, the fitting of GPD was expected to represent the characteristics of the distribution of extreme wave heights. The quantiles estimated using the determined probability density function (PDF) were in good agreement with the observed quantiles from altimeter data near the IORS and the Donghae buoy. The estimated 25-year and 50-year return period SWHs were $11.83 \mathrm{~m}$ and $13.95 \mathrm{~m}$ for the satellite SWH data near the IORS, respectively (Table 2). The 100-year return period SWHs were estimated to be $16.49 \mathrm{~m}$ for the altimeter data near the IORS. The estimated extreme SWHs were higher than the maximum SWHs with difference values of $3.66 \mathrm{~m}$ and $0.20 \mathrm{~m}$ around the IORS and the Donghae buoy, respectively. Considering that the estimated 100-year return period SWHs were higher than the maximum values, it may be reasonable to estimate extreme SWH by applying the PoT method for the study area. 

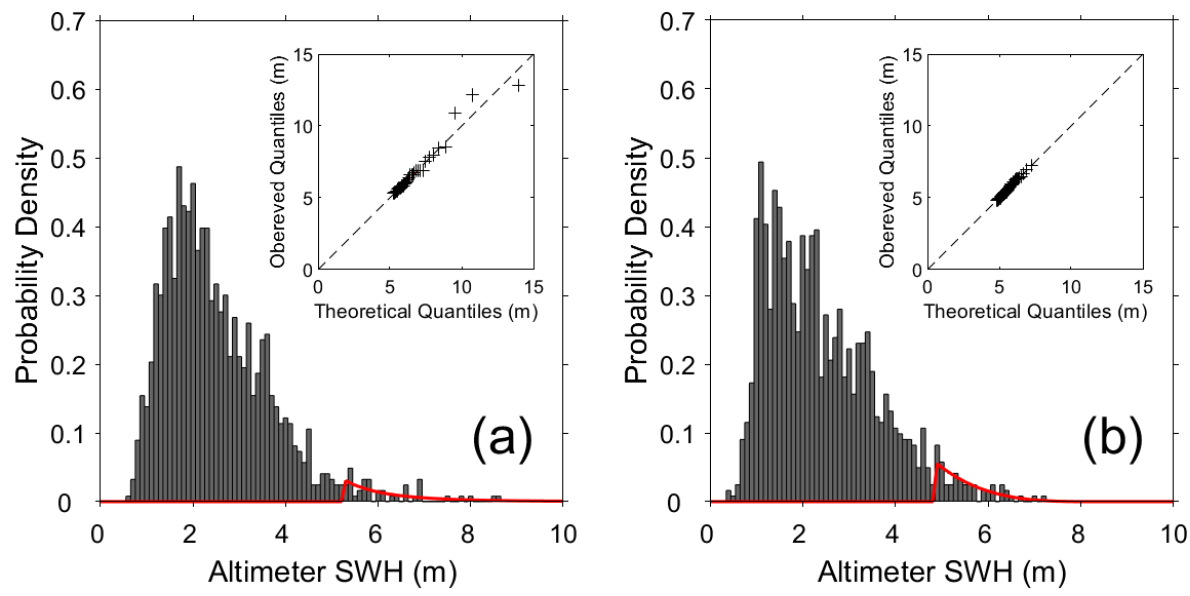

Figure 7. Distribution of probability density of significant wave height values from satellite altimeter data in the sea around (a) the IORS and (b) the Donghae buoy, where the red line represents the generalized Pareto distribution fitted to the data. The inner plots are the comparisons between observed quantiles and retrieved quantiles from Peak over Threshold analysis.

Table 2. SWH maximum $\left(H_{s}^{\text {Max }}\right)$ and $H_{s}^{25}, H_{s}^{50}$, and $H_{s}^{100}(\mathrm{~m})$ estimated by Peak over Threshold analyses using satellite altimeter data in the seas around the IORS and Donghae buoy, where $H_{s}^{M a x}$ represents the maximum value of measurements, and $H_{s}^{25}, H_{s}^{50}$, and $H_{s}^{100}$ are 25-year, 50-year, and 100 -year return period wave heights, respectively.

\begin{tabular}{|c|c|c|c|c|c|}
\hline Station & $H_{s}^{M a x}$ & $H_{s}^{25}$ & $H_{s}^{50}$ & $H_{s}^{100}$ & $H_{s}^{100}-H_{s}^{M a x}$ \\
\hline IORS & 12.83 & 11.83 & 13.95 & 16.49 & 3.66 \\
\hline Donghae Buoy & 7.23 & 7.03 & 7.25 & 7.43 & 0.20 \\
\hline
\end{tabular}

Figure 8 shows the estimated SWHs, marked red lines, as a function of the return periods from 1 year to 100 years using satellite data near the IORS and the Donghae buoy. The dash lines represent the upper and lower limits of the estimated SWHs within 95\% confidence interval. The confidence interval was calculated by using variance-covariance matrix and the delta method as described in [17]. In the sea near the IORS, the satellitebased extreme SWH at 100-year return period was relatively large of $16.49 \mathrm{~m}$ with a confidence interval of approximately $5.04 \mathrm{~m}$. In the region near the Donghae buoy in the eastern coastal region of the Korean Peninsula with deep water depth, however, the 100-year return period of SWH was $7.43 \mathrm{~m}$ with the upper and lower limits of the estimated return level amounted to $7.94 \mathrm{~m}$ and $6.93 \mathrm{~m}$. 

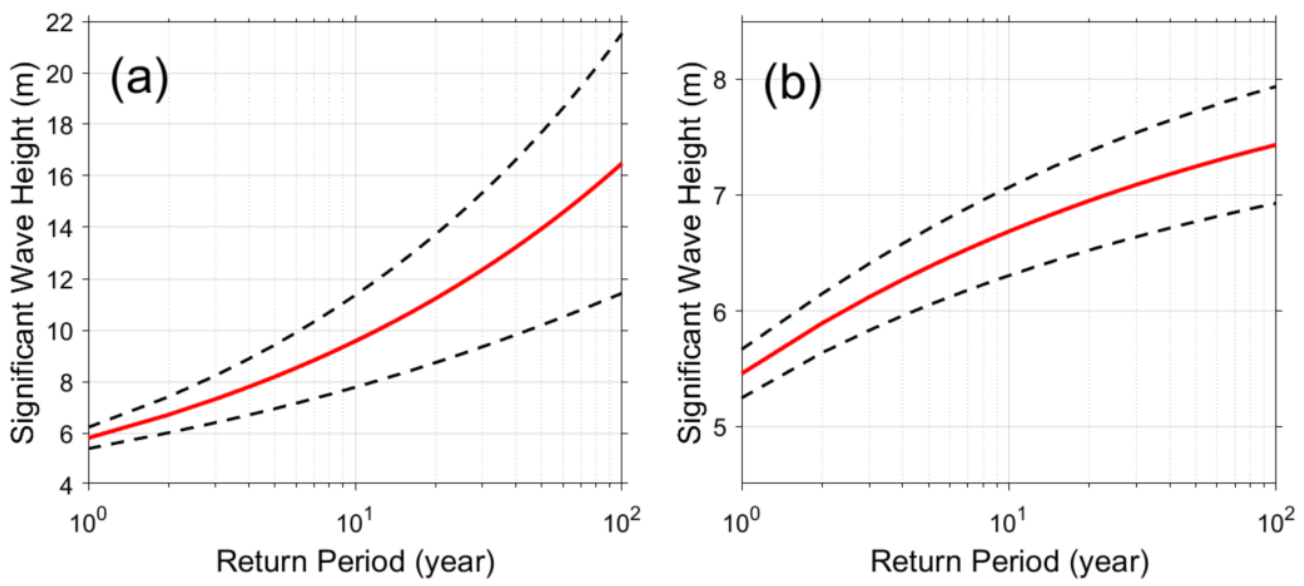

Figure 8. Distribution of extreme significant wave height estimates (red line) with respect to return periods from 1 year to 100 years near (a) the IORS and (b) the Donghae buoy, where the dash lines represent the upper and lower limits of the $95 \%$ confidence interval.

\subsection{Spatial Distribution of Extreme Significant Wave Heights from Altimeter Data}

To understand the spatial distribution of extreme SWHs in the Northwest Pacific, the 100-year return period SWHs within a bin of $2^{\circ} \times 2^{\circ}$ were estimated using the PoT method (Figure 9). To compare the magnitude of the deviation of 100-year extreme SWHs from the maximum SWHs over the past decades, we computed the mean values of SWHs within the upper $0.1 \%$ at each bin (Figure $9 a$ ). The number of SWHs within this upper limit generally accounted for approximately 100 out of approximately $10^{5}$ individual observations in a bin. The spatial distribution of the upper $0.1 \%$ mean SWHs showed a clear contrast between the western continental side, with small values of less than $8 \mathrm{~m}$, in the Yellow Sea and the East Sea (Sea of Japan) and the eastern open ocean side of the Northwest Pacific, with high values of over 12-13 m (Figure 9a).
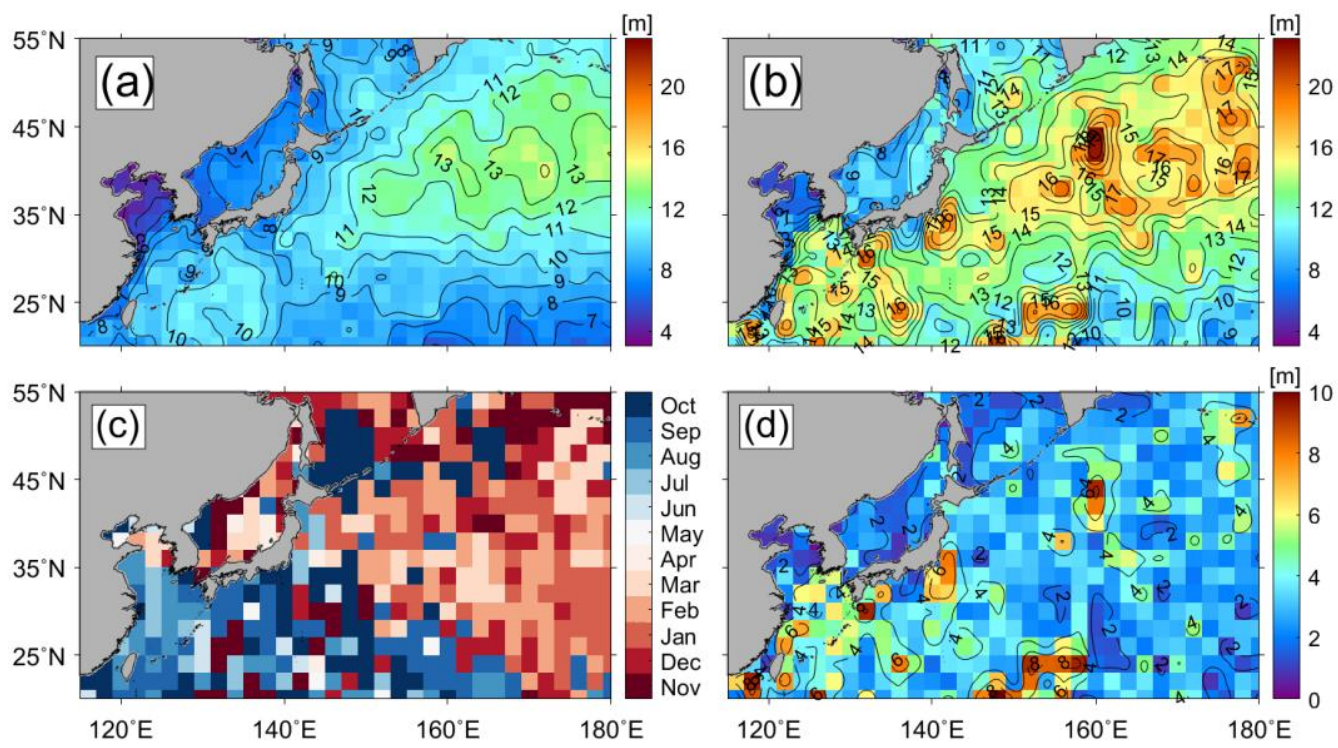

Figure 9. Spatial distribution of (a) significant wave height (SWH) within upper $0.1 \%(\mathrm{~m})$, (b) 100-year return period SWH (m) estimated by Peak over Threshold (PoT) analysis with a generalized Pareto distribution, (c) time of SWH within upper $0.1 \%$ in each grid (in months), and (d) difference between extreme SWH from PoT analysis and SWH within upper $0.1 \%$ (m). 
Compared with the upper $0.1 \%$ SWHs, the 100 -year return period extreme values based on the PoT analysis were much higher than the maximum SWHs over the period from 1992 to 2016 (Figure 9b). The PoT analysis indicates that the overall distribution of the 100-year return period SWHs ranged from 5 to $22 \mathrm{~m}$. High SWH values were estimated in the open ocean at high-latitude regions above $40^{\circ} \mathrm{N}$. It is noted that the wave heights of 14-15 $\mathrm{m}$ in the East China Sea can be found in the results of the PoT analysis. A strong spatial variability of extreme SWHs estimated with PoT is inferred from the high winds with spatially dominant fluctuations in the Northwest Pacific region in winter. In addition, the irregular movement of typhoons in summer and fall is believed to cause an unsystematic imbalance in space. Figure $9 \mathrm{c}$ shows the highly frequent occurrence time of high SWH values, by investigating the highest frequency of SWHs within the upper $0.1 \%$. This reveals a contrast distinction between the northeastern part in winter and the southwestern part in summer. This implies that the extreme SWHs of the East China Sea and southern region of the Northwest Pacific might be induced by typhoons in summer and fall. In the northern region, the strong winds in winter seem to be responsible for the high 100-year extreme SWHs. The difference between the 100-year return period SWH and the maximum SWH showed positive values of 6-8 $\mathrm{m}$ in the East China Sea, southern $\left(<25^{\circ} \mathrm{N}\right)$ and northern regions $\left(>40^{\circ} \mathrm{N}\right)$ of the Northwest Pacific (Figure 9d). Obvious positive differences greater than $6 \mathrm{~m}$ were observed in the typhoon region.

\subsection{Seasonal Variability of Mean and Maximum Significant Wave Heights}

To understand the differences between the 100-year extreme SWHs and the mean SWHs over the past decades, we investigated the monthly distributions of SWHs for the period of 1992 to 2016, which are shown in Figure 10. The extremely large values of mean SWHs appeared in the eastern part of the Northwest Pacific, at approximately $5 \mathrm{~m}$ at $175^{\circ} \mathrm{E}$, $38^{\circ} \mathrm{N}$ in November and a broad region of about 4.2-5.0 $\mathrm{m}$ in October and December. In January, the SWHs were still high but began to decrease by less than $3 \mathrm{~m}$ in the northeastern region. In the spring, from March to May, the SWHs were remarkably reduced to less than $1 \mathrm{~m}$ in the marginal seas. This tendency of relatively small SWHs $(<1 \mathrm{~m})$ in the marginal seas lasted from summer June to August. Therefore, the spatial distribution of the 100-year return period SWHs with the PoT analysis in Figure 9 could be asserted to reflect the characteristics of the extreme conditions in the northeastern part of winter. Considering the relatively small SWHs in the East China Sea in summer, the extreme SWHs in this region originate from the activity of typhoons rather than ordinary SWHs in summer.

As mentioned previously, the mean SWHs were relatively small, at less than $1.5 \mathrm{~m}$ in the East China Sea in summer. This yielded high differences from the 100-year return period SWHs in this region. Accordingly, the seasonal variations of extreme SWHs within the upper $0.1 \%$ were examined, as shown in Figure 11. Similar to the seasonal mean of the SWHs, the extreme SWHs also represented the highest values, of up to $14 \mathrm{~m}$, in the eastern part in winter from December to February (Figure 11d). One of the most remarkable differences between the means of all SWHs (Figure 10) and the extreme SWHs within the upper $0.1 \%$ (Figure 11) was found in summer and fall. There were high values of extreme SWHs amounting to 8-10 $\mathrm{m}$ in the East China Sea and south of Japan in the Northwest Pacific. This implies that some of the high SWHs occur seldomly but appear with extremely high wave heights in summer and fall. This suggests a potential role for tropical storms in the regions during summer and fall. 

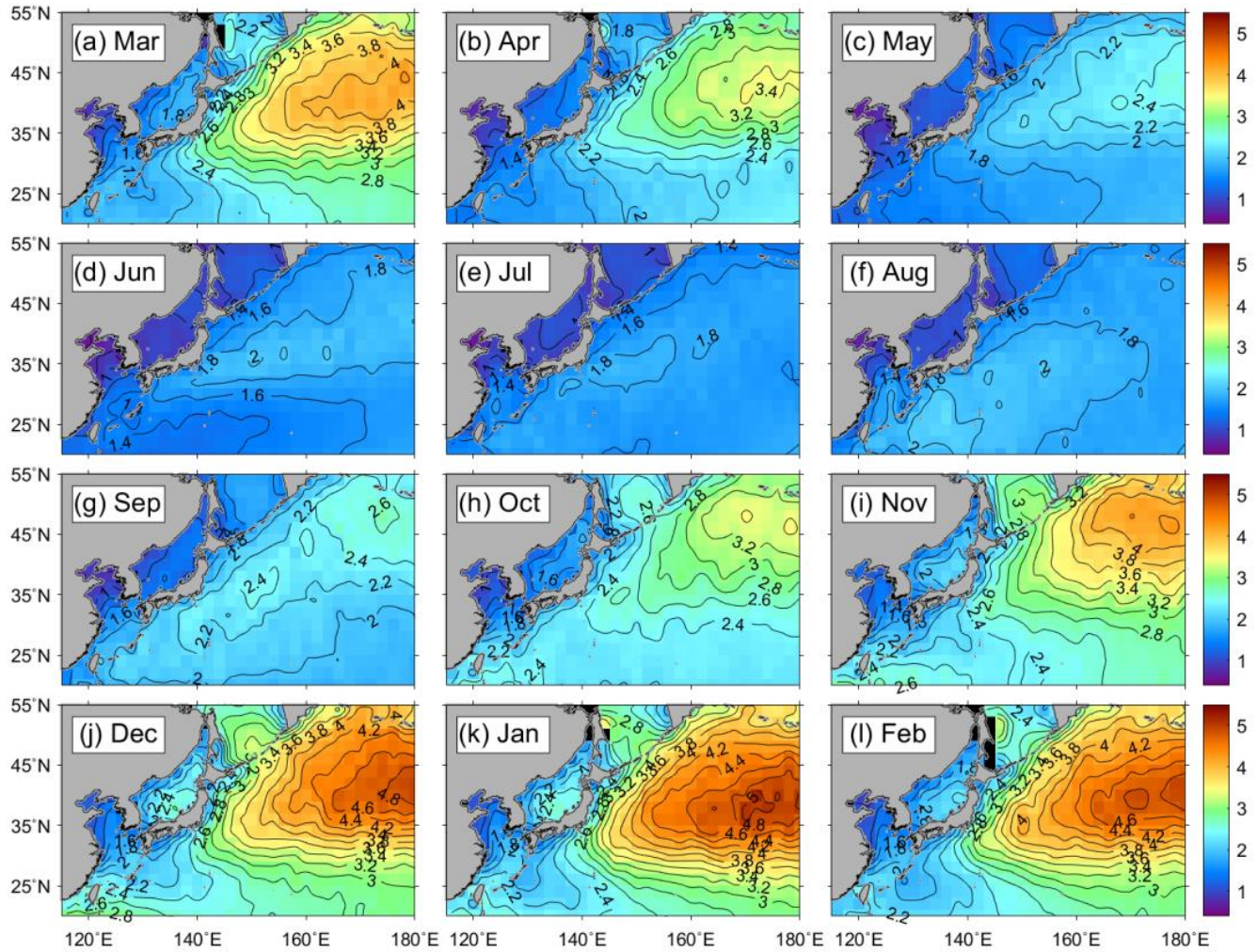

Figure 10. Monthly maps of satellite significant wave heights in the Northwest Pacific for the period 1992 to 2016: (a) March, (b) April, (c) May, (d) June, (e) July, (f) August, (g) September, (h) October, (i) November, (j) December, (k) January, and (1) February.
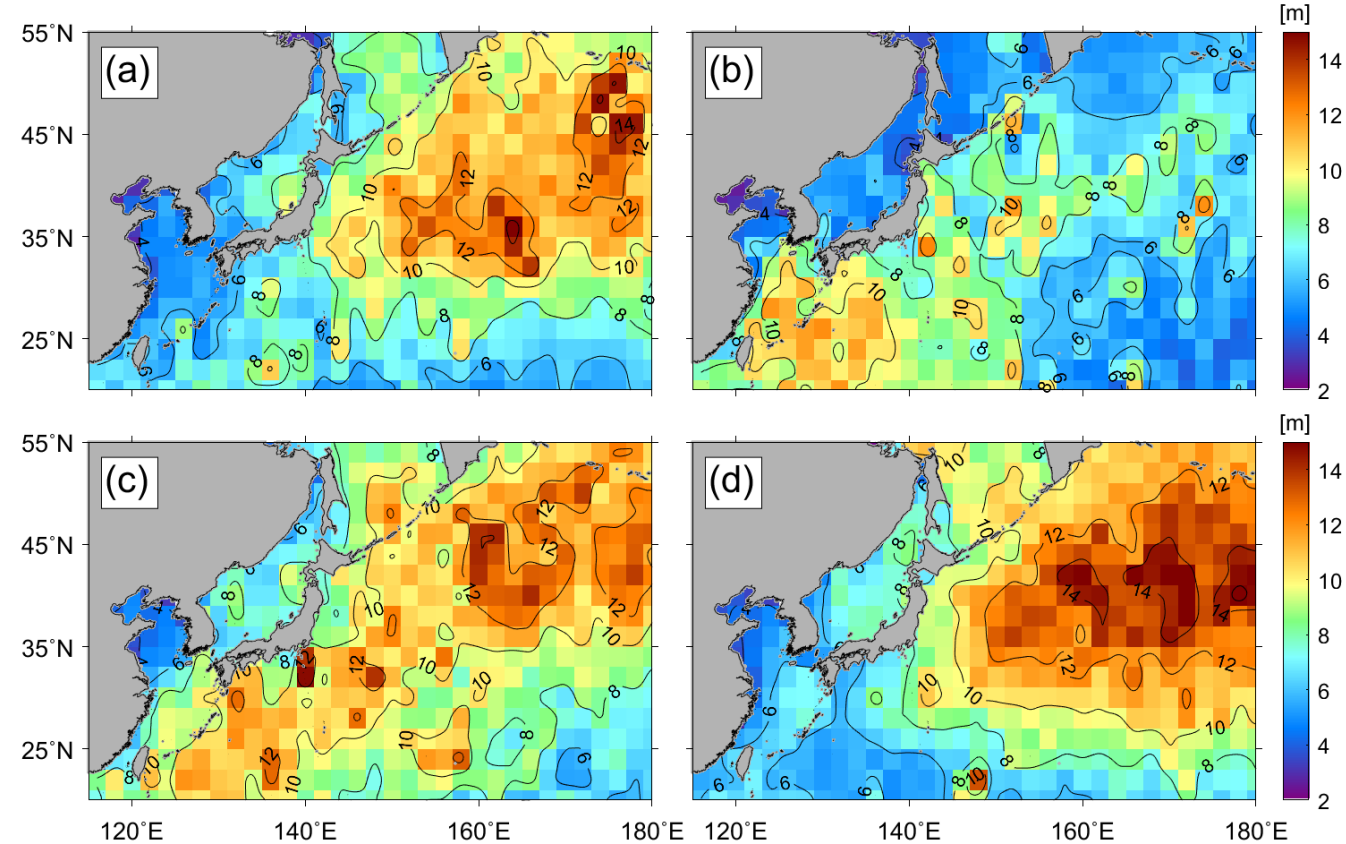

Figure 11. Seasonal distribution of significant wave heights from satellites within the upper $0.1 \%$ in the Northwest Pacific in (a) spring (March, April, and May), (b) summer (June, July, and August), (c) fall (September, October, and November), and (d) winter (December, January, and February) for the period of 1992 to 2016. 


\subsection{Seasonal Variation of 100-Year Return Significant Wave Heights}

The relatively weak seasonal variation of the estimated extreme 100-year return SWH using the PoT analysis was found in the Northwest Pacific (Figure 12). The spatial average of the 100-year return period SWH with the PoT analysis was estimated to be about $10 \mathrm{~m}$ in the winter. In contrast, it was calculated to be about $8.3 \mathrm{~m}$ in the summer, which was approximately $1 \mathrm{~m}$ higher than the maximum values of the upper $0.1 \%$ of SWHs (Figure 11). The overall results of the PoT analysis showed a similar spatial pattern to the upper $0.1 \%$ of SWHs, but due to the limited data and high spatial variability, some abnormal values can be seen in the study area. In winter and spring, extreme SWHs had a tendency to be high at relatively high latitudes $\left(>40^{\circ} \mathrm{N}\right)$. As described earlier, the highest extreme $\mathrm{SWH}$ region $(>10 \mathrm{~m})$ in the East China Sea during summer (Figure 12b) seemed to be due to the effect of typhoons (Figure 1c,d). The effects of extreme conditions and latitudinal tendencies were also detected in the fall (Figure 12c).
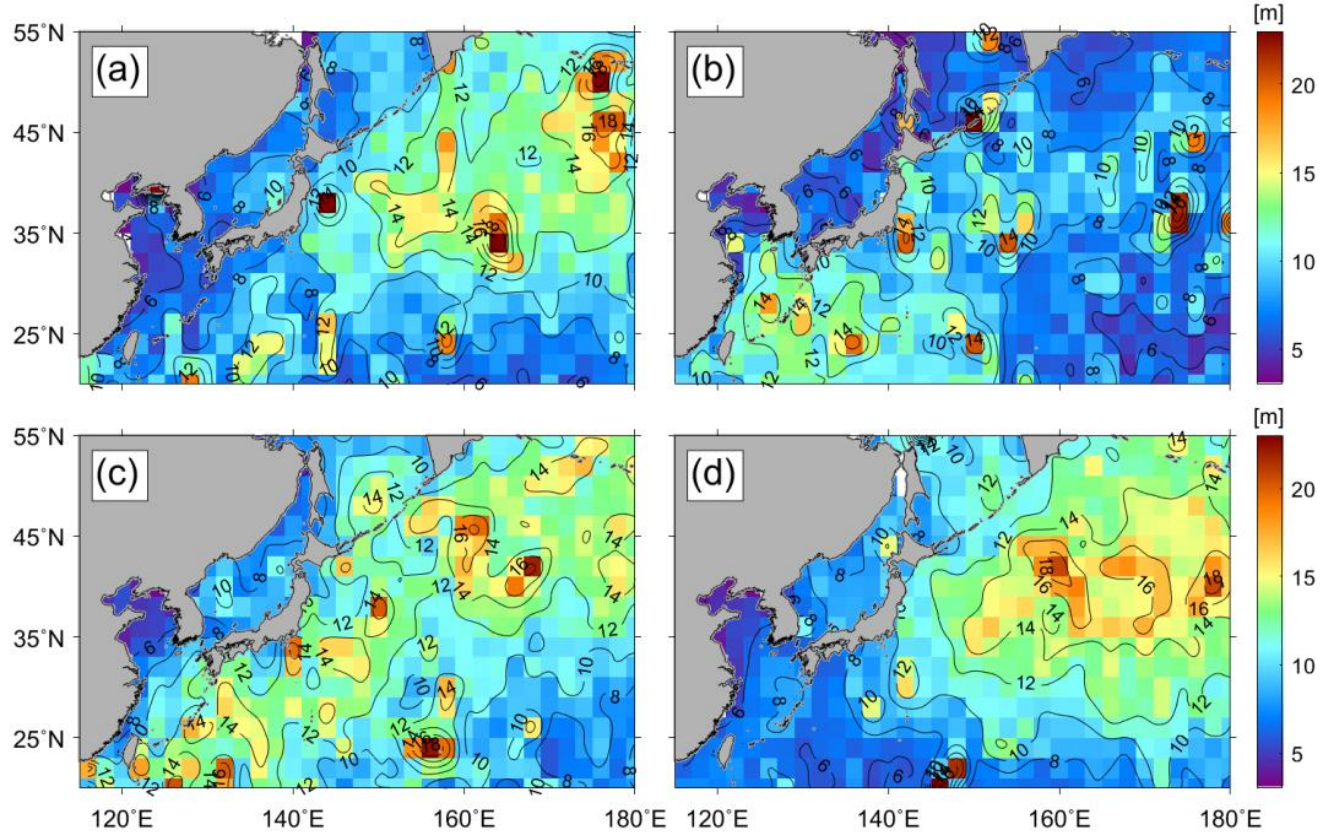

Figure 12. Spatial distribution of seasonal extreme $\mathrm{SWH}\left(H_{S}^{100}\right)(\mathrm{m})$ estimated by the PoT method in (a) spring (March, April, and May), (b) summer (June, July, and August), (c) fall (September, October, and November), and (d) winter (December, January, and February).

Although the mean SWHs and the upper $0.1 \%$ of SWHs appeared remarkably in winter (Figure 10d,j-1), the spatially dominant PoT-based extreme SWHs appeared to be randomly distributed with values from $14 \mathrm{~m}$ to $18 \mathrm{~m}$. The maximum 100-year SWHs were $18 \mathrm{~m}$ in spring, $16 \mathrm{~m}$ in summer, $16 \mathrm{~m}$ in fall, and $18 \mathrm{~m}$ in winter. This implies that the PoT-based SWHs appear regardless of season and locations with slight differences as shown in Figure 12.

\subsection{Effect of Tropical Cyclones on the Estimation of Extreme SWH}

In the previous sections, it was hypothesized that high PoT-based SWHs in summer were associated with typhoons. To clarify whether these are indeed related to typhoons, we classified all the spatial grids into two regions of typhoon and non-typhoon by applying a limit to the number of typhoons $(\mathrm{N}=10)$ in each bin. Figure 13a shows the histogram of the differences between PoT-derived extreme SWHs and the maximum SWH in the typhoon region with a frequency of greater than 10, corresponding to a cumulative percentage of typhoon passage frequency of $60 \%$ approximately as shown in Figure 1c,d. The differences between the 100-year return SWH obtained from the PoT analysis and the maximum SWHs showed positive values in nearly all regions $(>99.5 \%)$ regardless of the number of 
typhoons, which indicated that the characteristics of extreme conditions were appropriately reflected in the EVA (Figure 13a,d). The maximum count was found at approximately $4 \mathrm{~m}$, which was similar to that of non-typhoon regions, as shown in Figure 13d. Although the maximum frequency appeared at a difference of the SWHs in both typhoon and nontyphoon regions, their occurrence months, with a high frequency of high SWHs within the upper $0.1 \%$, differed as they appeared in August to October in the case of typhoon regions (Figure 13b) and in December to February in the case of non-typhoon regions (Figure 13e). In total, $56.6 \%$ of the typhoon regions appeared to present the maximum SWH between August and October, whereas $67.5 \%$ of the non-typhoon region showed the maximum value in winter. The PoT-derived SWHs showed a high frequency in fall (from September to November) in the typhoon region, while the maximum frequency appeared in winter (December to February) in the non-typhoon region, as shown in Figure 13c,f. The time of the maximum value of the extreme SWHs estimated by the PoT analysis was similar to that of the maximum SWH, which also demonstrated that the PoT analysis appropriately simulated the characteristics of extreme SWH in the Northwest Pacific.
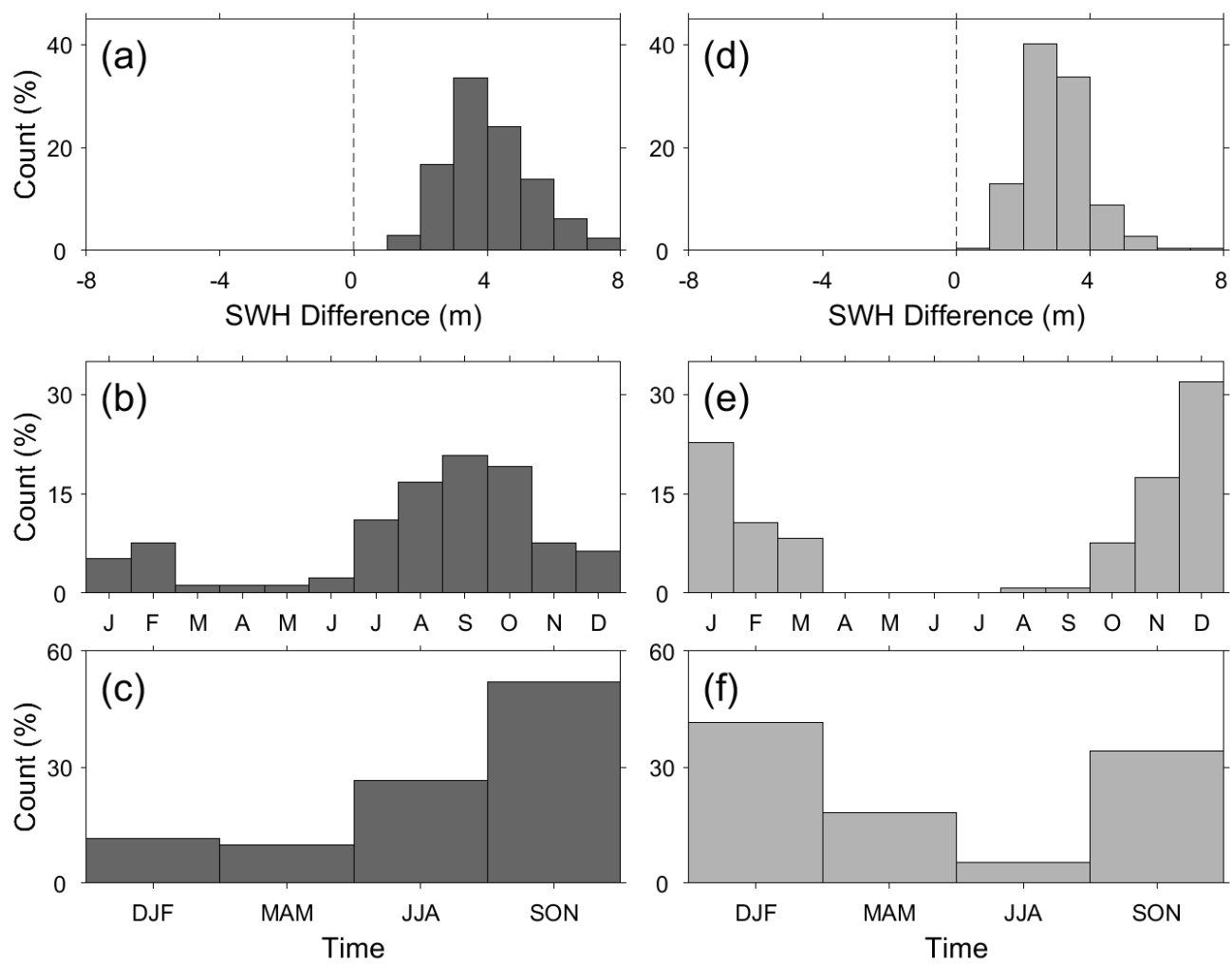

Figure 13. Histograms of (a) differences between extreme SWHs using PoT and SWHs within upper 0.1\%, (b) time (in month) of SWHs within upper $0.1 \%$, (c) time of the maximum value of extreme SWHs using PoT in the typhoon region, with a number of typhoons greater than 10 , and $(\mathbf{d}-\mathbf{f})$ the cases for the non-typhoon region with a number of typhoons of less than 10 .

The distributions of SWHs showed considerable differences between the typhoon region and in the non-typhoon region. In order to investigate the characteristics of SWH distribution in the typhoon and non-typhoon region in more detail, two points representing the typhoon $\left(128^{\circ} \mathrm{E}, 30^{\circ} \mathrm{N}\right)$ and non-typhoon $\left(174^{\circ} \mathrm{E}, 52^{\circ} \mathrm{N}\right)$ region were selected, and the PDFs were determined by PoT analysis (Figure 14). In the selected point representing the typhoon region $\left(128^{\circ} \mathrm{E}, 30^{\circ} \mathrm{N}\right)$, about 30 typhoons passed over the study period. As expected, the quantiles estimated by the PoT analysis showed relatively good agreement with the observed quantiles (Figure 14a). In addition, as shown in Figure 14b, the PoT analysis estimated appropriate extreme SWHs in the point representing the non-typhoon region. With the accumulation of satellite-observed SWH data over several decades, it 
can also be suggested that the PoT analysis can be used to estimate more reliable extreme SWHs in the Northwest Pacific.
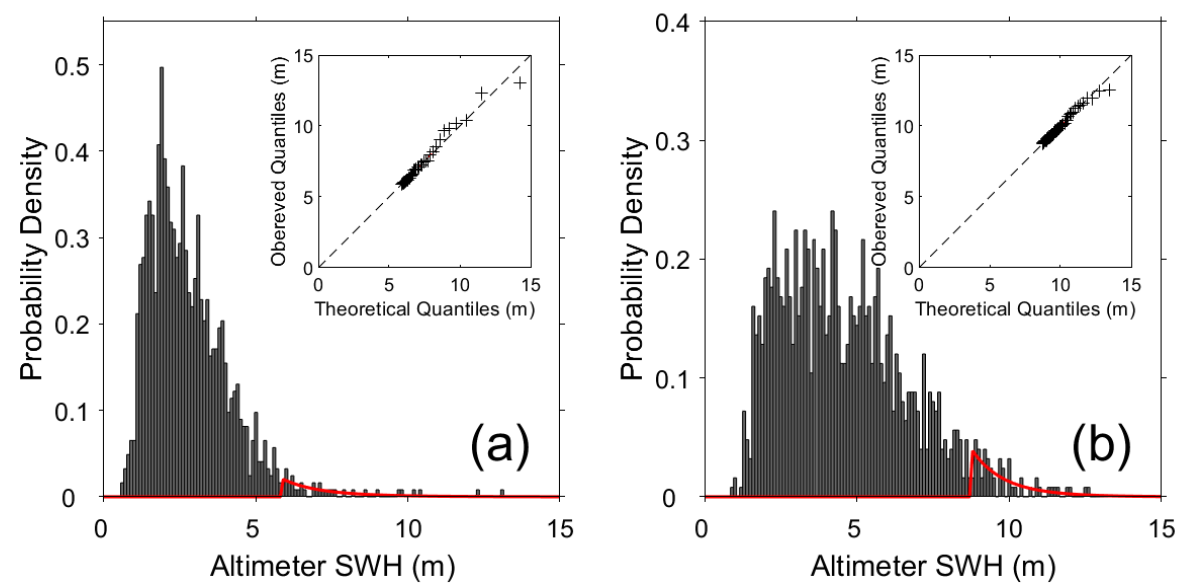

Figure 14. Histograms of the PoT analysis with the generated Pareto distribution in (a) the typhoon region $\left(128^{\circ} \mathrm{E}, 30^{\circ} \mathrm{N}\right)$ with a frequency of more than 10 and $(\mathbf{b})$ non-typhoon region $\left(174^{\circ} \mathrm{E}, 52^{\circ} \mathrm{N}\right)$ with a frequency of less than 10.

\section{Discussion}

Although extreme SWHs from PoT analysis are evaluated reliably in the Northwest Pacific, where typhoons are frequently generated, this method may also have some limitations. Figure 15 shows the $11 \mu \mathrm{m}$ channel image of COMS/MI from 26 to 27 August 2012, when the typhoon Bolaven transected the Korean Peninsula. In Figure 15, all the altimeter data along the tracks of SWH observations were within $3 \mathrm{~h}$ of the COMS/MI observation time. Typhoon Bolaven passed near the IORS at 15 UTC on 27 August 2012, and an enormous SWH with a peak value of $11.1 \mathrm{~m}$ was measured by the instrument from the IORS (Figure 3). At nearly the same time, the altimeter observed an SWH of about $12 \mathrm{~m}$ while passing through the center of the typhoon (Figure 15g). As may be observed from the time series of the altimeter observations in Figure 15, the altimeters did not obtain data for the entirety of the storm, although all satellite altimeter data from Jason-1/2 and Cryosat-2 were collected. Therefore, it is highly plausible that extreme SWHs may be underestimated in regions in which the altimeter is unable to observe the high SWHs generated by storms. The observation limit of the altimeter is reported to be sensitive to PoT analysis [28]. In order to calculate the extreme wave heights with high confidence, the duration of the wave height data should be sufficiently long. Especially in the Northwest Pacific, where typhoons occur irregularly in space and time, the amount of satellite data should be accumulated over a longer period in order to include the effects of typhoons.

Both buoys and altimeters have limitations on the measurements of extreme waves because the buoys measure instantaneous extreme waves in a single point and satellite altimeters measure a mean value in a footprint. Thus, a difference in the resulting measurements will inevitably appear. Despite the differences in these observations, field observations of wave heights are very important and provide us with invaluable verification data. In this regard, observational data from the IORS in the center of the East China Sea can provide very important clues regarding wave height changes as well as other oceanic and atmospheric values when typhoons or extreme events occur. In light of this, if sufficient data are accumulated, the IORS can be one of the most important sites for the validation of extreme SWHs using satellite data and for diverse kinds of oceanic research. Thus, more buoy stations for in situ measurements should be installed and operated in near-real time for the high-performance estimation of 100-year period extreme SWHs. 

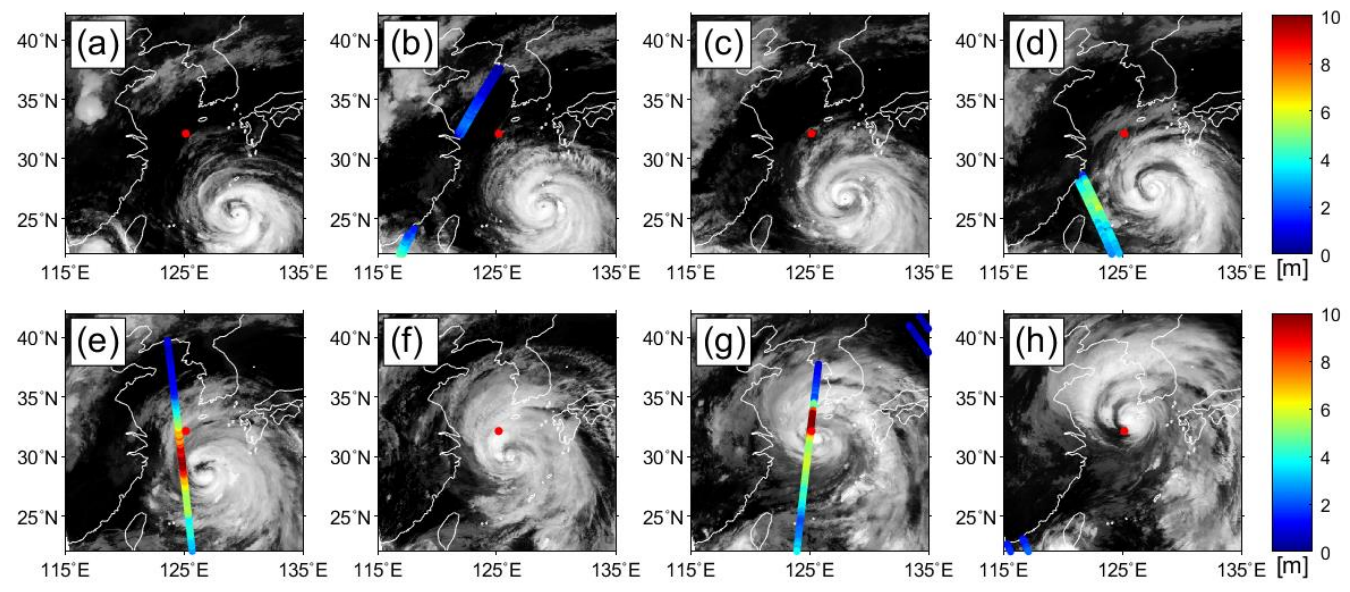

Figure 15. Spatial distribution of along-track SWHs around the tropical cyclone named Bolaven at (a) 00 UTC, (b) 06 UTC, (c) 12 UTC, and (d) 18 UTC on 26 August 2012 and (e) 00, (f) 06, (g) 12, and (h) 18 UTC on 27 August 2012, where the backgrounds are infrared images from the Communication, Ocean, and Meteorological Satellite/Meteorological Imager (COMS/MI) and the red dot denotes the location of the Ioedo Ocean Research Center. The SWH data were obtained from satellite altimeters of (b) Jason-1 (right) and Jason-2 (left), (d) Jason-1 (right) and Jason-2 (left), (e) Cryosat-2, (g) Cryosat-2 (middle), Jason-1 (right) and Jason-2 (left) in the upper right corner, and (h) Jason-1 (right) and Jason-2 (left).

\section{Conclusions}

The 100-year return period of SWHs was estimated by applying the PoT method as one of representative EVA methods. The PoT-derived SWHs were compared with the maximum SWHs within the upper $0.1 \%$ of satellite observations in the Northwest Pacific. Despite many shortcomings, including the limitations of the PoT method and the unevenness of observations in satellite altimeter data, the PoT method supported our hypothesis by presenting higher SWHs than the maximum values observed from 1992 to 2016. The comparisons of the data were performed by classifying the extreme SWHs into two different regions-a typhoon region and non-typhoon region-by defining the thresholds of the frequency of the number of typhoons in each bin. As a result, the PoTderived 100-year extreme SWHs revealed the characteristic variations affected by not only typhoons in the East China Sea during typhoon periods in summer and fall but also by winter-time high SWHs in the northeastern part of the study region in the Northwest Pacific. Overall differences of SWHs between PoT-derived extremes and the maximum values appeared at approximately $4 \mathrm{~m}$, and the highest differences were approximately $8 \mathrm{~m}$.

The present PoT method represents the SWHs in extreme events well. However, there is a potential limitation in terms of bias due to the few sampling problems when an altimeter observes the SWH along the track in the nadir direction. Nonetheless, satellite altimeter data are very valuable for estimating the extreme value of SWHs as they cover the global ocean as well as regional seas. In addition, if sufficient data are accumulated, it is also expected that the IORS could be a good candidate for investigating oceanic responses to the typhoons that frequently pass over the station.

Author Contributions: Conceptualization, K.-A.P.; data curation, H.-J.W.; methodology, H.-J.W. and K.-A.P.; writing —original draft preparation, H.-J.W.; writing—review and editing; K.-A.P. All authors have read and agreed to the published version of the manuscript.

Funding: This work was supported by the National Research Foundation of Korea (NRF), grant funded by the Korean government (MSIT) (No. 2020R1A2C2009464) and partly by "Deep Water Circulation and Material Cycling in the East Sea" (1525010256) funded by the Ministry of Oceans and Fisheries, Korea. 
Data Availability Statement: All data used in this study are available from IFREMER (satellite altimeter SWH data, ftp: / ftp.ifremer.fr/ifremer/cersat/products/swath/altimeters/waves / (accessed on 20 January 2021)), KMA (buoy and COMS data, https:/ / nmsc.kma.go.kr/ (accessed on 20 January 2021)), or KHOA (IORS data, http:/ / www.khoa.go.kr/ (accessed on 20 January 2021)).

Acknowledgments: In situ data from the Ieodo Ocean Research Station (IORS) was provided by the IORS project of the Korean Hydrographic and Oceanographic Agency, Korea.

Conflicts of Interest: The authors declare no conflict of interest.

\begin{tabular}{|c|c|}
\hline Abbreviat & \\
\hline The followir & abbreviations are used in this manuscript: \\
\hline $\mathrm{AM}$ & Annual Maximum \\
\hline COMS/MI & Communication, Ocean, and Meteorological Satellite/Meteorological Imager \\
\hline Envisat & Environmental Satellite \\
\hline ERS-1 & European Remote Sensing-1 \\
\hline ERS-2 & European Remote Sensing-2 \\
\hline EVA & extreme value analysis \\
\hline GPD & generalized Pareto distribution \\
\hline GFO & Geosat Follow-On \\
\hline IORS & Ieodo Ocean Research Station \\
\hline IDM & Initial Distribution Method \\
\hline IFREMER & Institut Français de Recherche pour l'Exploitation de la Mer \\
\hline IBTrACS & International Best Track Archive for Climate Stewardship \\
\hline Jason-1 & Joint Altimetry Satellite Oceanography Network-1 \\
\hline Jason-2 & Joint Altimetry Satellite Oceanography Network-2 \\
\hline KMA & Korea Meteorological Administration \\
\hline PoT & Peak over Threshold \\
\hline PDF & probability density function \\
\hline RMSE & root-mean-square error \\
\hline SARAL & Satellite for Argos and Altika \\
\hline SWH & significant wave height \\
\hline TOPEX & Topography Experiment \\
\hline
\end{tabular}

\section{References}

1. Webster, P.J.; Holland, G.J.; Curry, J.A.; Chang, H.-R. Changes in tropical cyclone number, duration, and intensity in a warming environment. Science 2005, 309, 1844-1846. [CrossRef] [PubMed]

2. Knutson, T.R.; McBride, J.L.; Chan, J.; Emanuel, K.; Holland, G.; Landsea, C.; Held, I.; Kossin, J.P.; Srivastava, A.; Sugi, M. Tropical cyclones and climate change. Nat. Geosci. 2010, 3, 157. [CrossRef]

3. Kossin, J.P.; Emanuel, K.A.; Vecchi, G.A. The poleward migration of the location of tropical cyclone maximum intensity. Nature 2014, 509, 349-352. [CrossRef]

4. Park, D.-S.R.; Ho, C.H.; Kim, J.H. Growing threat of intense tropical cyclone to East Asia over the period 1977-2010. Environ. Res. Lett. 2014, 9, 014008. [CrossRef]

5. Lin, I.-I.; Chan, J.C.; Chan, J.C.L. Recent decrease in typhoon destructive potential and global warming implications. Nat. Commun. 2015, 6, 7182. [CrossRef] [PubMed]

6. Allan, J.C.; Komar, P.D. Are ocean wave heights increasing in the eastern North Pacific? EOS 2000, 47, 561-567. [CrossRef]

7. Ruggiero, P.; Komar, P.D.; Allan, J.C. Increasing wave heights and extreme value projections: The wave climate of the U.S. Pacific Northwest. Coast. Eng. 2010, 57, 539-552. [CrossRef]

8. Semedo, A.; SušElj, K.; Rutgersson, A.; Sterl, A. A global view on the wind sea and swell climate and variability from ERA-40. J. Clim. 2011, 24, 1461-1479. [CrossRef]

9. Young, I.R.; Zieger, S.; Babanin, A.V. Global trends in wind speed and wave height. Science 2011, 332, 451-455. [CrossRef] [PubMed]

10. Young, I.R.; Ribal, A. Multi-platform evaluation of global trends in wind speed and wave height. Science 2019, 364, 548-552. [CrossRef] [PubMed]

11. Church, J.A.; White, N.J. A 20th century acceleration in global sea-level rise. Geophys. Res. Lett. 2006, 33. [CrossRef]

12. Rahmstorf, S. A Semi-Empirical Approach to Projecting Future Sea-Level Rise. Science 2007, 315, 368-370. [CrossRef] [PubMed]

13. Stocker, T.F.; Qin, D.; Plattner, G.-K.; Tignor, M.; Allen, S.K.; Boschung, J.; Nauels, A.; Xia, Y.; Bex, V.; Midgley, P.M. Climate Change 2013: The Physical Science Basis: Contribution of Working Group I to the Fifth Assessment Report of the Intergovernmental Panel on Climate Change; Cambridge University Press: Cambridge, UK; New York, NY, USA, 2013; p. 1535. 
14. Goda, Y. On the methodology of selecting design wave height. In Proceedings of the 21st International Conference on Coastal England, Malaga, Spain, 20-25 June 1988.

15. Mathiesen, M.; Goda, Y.; Hawkes, P.J.; Mansard, E.; Martín, M.J.; Peltier, E.; Thompson, E.F.; Van Vledder, G. Recommended practice for extreme wave analysis. J. Hydraul. Res. 1994, 32, 803-814. [CrossRef]

16. Goda, Y. Random Seas and Design of Maritime Structures; World Scientific Publishing Co. Pte. Ltd.: Singapore, $2010 ;$ p. 708.

17. Coles, S. An Introduction to Statistical Modelling of Extremes; Springer: Berlin, Germany, 2001.

18. Carter, D.J.; Challenor, P.G. Estimating return values of environmental parameters. Q. J. R. Meteorol. Soc. 1981, 107, 259-266. [CrossRef]

19. Ferreira, J.A.; Soares, C.G. An Application of the Peaks over Threshold Method to Predict Extremes of Significant Wave Height. J. Offshore Mech. Arct. Eng. 1998, 120, 165. [CrossRef]

20. Challenor, P.G.; Wimmer, W.; Ashton, I. Climate change and extreme wave heights in the North Atlantic. In Proceedings of the Envisat and ERS Symposuim, Salzburg, Austria, 6-10 September 2005.

21. Mendez, F.J.; Mendez, M.; Luceno, A.; Losada, I.J. Estimation of the long-term variability of extreme significant wave height using a time-dependent Peak over Threshold (PoT) model. J. Geophys. Res. 2006, 111, 1-13. [CrossRef]

22. Menéndez, M.; Méndez, F.J.; Losada, I.J.; Graham, N.E. Variability of extreme wave heights in the northeast Pacific Ocean based on buoy measurements. Geophys. Res. Lett. 2008, 35, L22607. [CrossRef]

23. Sartini, L.; Cassola, F.; Besio, G. Extreme waves seasonality analysis: An application in the Mediterranean Sea. J. Geophys. Res. Oceans 2015, 120, 6266-6288. [CrossRef]

24. Alves, J.H.G.M.; Young, I.R. On estimating extreme wave heights using combined Geosat, Topex/Poseidon and ERS-1 altimeter data. Appl. Ocean. Res. 2003, 25, 167-186. [CrossRef]

25. Wimmer, W.; Challenor, P.; Retzler, C. Extreme wave heights in the North Atlantic from altimeter data. Renew. Energ. 2006, 31, 241-248. [CrossRef]

26. Izaguirre, C.; Mendez, F.J.; Menéndez, M.; Luceño, A.; Losada, I.J. Extreme wave climate variability in southern Europe using satellite data. J. Geophys. Res. Space Phys. 2010, 115, 04009. [CrossRef]

27. Izaguirre, C.; Mendez, F.J.; Menendez, M.; Losada, I.J. Global extreme wave height variability based on satellite data. Geophys. Res. Lett. 2011, 38. [CrossRef]

28. Vinoth, J.; Young, I.R. Global estimates of extreme wind speed and wave height. J. Clim. 2011, 24, 1647-1665. [CrossRef]

29. Young, I.R.; Vinoth, J.; Zieger, S.; Babanin, A.V. Investigation of trends in extreme wave height and wind speed. J. Geophys. Res. 2012, 117, C00J06.

30. Takbash, A.; Young, I.R.; Breivik, O. Global wind speed and wave height extremes derived from satellite records. J. Clim. 2019, 32, 109-126. [CrossRef]

31. Wang, X.L.; Swail, V.R. Changes of extreme wave heights in Northern Hemisphere oceans and related atmospheric circulation regimes. J. Clim. 2001, 14, 2204-2221. [CrossRef]

32. Cañellas, B.; Orfila, A.; Méndez, F.; Menéndez, M.; Tintoré, J. Application of a PoT model to estimate the extreme significant wave height levels around the Balearic Sea (Western Mediterranean). J. Coast. Res. Spec. Issue 2007, 50, 329-333.

33. Meucci, A.; Young, I.R.; Breivik, O. Wind and wave extremes from atmosphere and wave model ensembles. J. Clim. 2018, 31, 8819-8893. [CrossRef]

34. Gao, H.; Shao, Z.; Wu, G.; Li, P. Study of Directional Declustering for Estimating Extreme Wave Heights in the Yellow Sea. J. Mar. Sci. Eng. 2020, 8, 236. [CrossRef]

35. Takbash, A.; Young, I.R. Long-Term and Seasonal Trends in Global Wave Height Extremes Derived from ERA-5 Reanalysis Data. J. Mar. Sci. Eng. 2020, 8, 1015. [CrossRef]

36. Woo, H.J.; Park, K.A. Long-term trend of satellite-observed significant wave height and impact on ecosystem in the East/Japan Sea. Deep Sea Res. Part II Top. Stud. Oceanogr. 2016, 143, 1-14. [CrossRef]

37. Neumann, C.J. Global Guide to Tropical Cyclone Forecasting; World Meteorological Organization: Geneva, Switzerland, 1993.

38. Liu, K.S.; Chan, J.C. Inactive Period of Western North Pacific Tropical Cyclone Activity in 1998-2011. J. Clim. 2013, 26, 2614-2630. [CrossRef]

39. Matsuura, T.; Yumoto, M.; Iizuka, S. A mechanism of interdecadal variability of tropical cyclone activity over the western North Pacific. Clim. Dyn. 2003, 21, 105-117. [CrossRef]

40. Osinowo, A.; Lin, X.; Zhao, D.; Wang, Z. Long-term variability of extreme significant wave height in the South China sea. Adv. Meteorol. 2016, 2016, 2419353. [CrossRef]

41. Kong, Y.; Zhang, X.; Sheng, L.; Chen, B. Validation and application of multi-source altimeter wave data in China's offshore areas. Acta Oceanol. Sin. 2016, 35, 86-96. [CrossRef]

42. Queffeulou, P.; Croizé-Fillon, D. Global Altimeter SWH Data Set; Laboratoire d'Océanographie Spatiale, IFREMER: Brest, France, 2017.

43. Ha, K.-J.; Nam, S.H.; Jeong, J.-Y.; Moon, I.-J.; Lee, M.; Yun, J.; Jang, C.; Kim, Y.; Byun, D.-S.; Heo, K.-Y.; et al. Observations utilizing Korean Ocean Research Stations and their Applications for Process Studies. Bull. Am. Meteor. Soc. 2019, 100, $2061-2075$. [CrossRef]

44. Intergovernmental Oceanographic Commission. GTSPP Real-Time Quality Control Manual; Manuals and Guides 22; UNESCO: Paris, France, 1990. 
45. Intergovernmental Oceanographic Commission. Manual of Quality Control Procedures for Validation of Oceanographic Data; Manuals and Guides 26; UNESCO: Paris, France, 1993.

46. Evans, D.; Conrad, C.; Paul, F. Handbook of Automated Data Quality Control Checks and Procedures of the National Data Buoy Center; NOAA/National Data Buoy Centre: Hancock, MS, USA, 2003; p. 44.

47. Lee, H.S. Abnormal storm waves in the East Sea (Japan Sea) in April 2012. J. Coast. Res. 2013, 65, 748-753. [CrossRef]

48. Heo, K.Y.; Choi, J.Y.; Jeong, S.H. Characteristics of High Swell-like Waves on East Coast of Korea Observed by Direct Measurements and Reanalysis Data Sets. J. Coast. Res. 2020, 95, 1433-1437. [CrossRef]

49. Knapp, K.R.; Kruk, M.C.; Levinson, D.H.; Diamond, H.J.; Neumann, C.J. The international best track archive for climate stewardship (IBTrACS). Bull. Am. Met. Soc. 2010, 91, 363-376. [CrossRef]

50. Cooper, C.K.; Forristall, G.Z. The use of satellite altimeter data to estimate the extreme wave climate. J. Atmos. Ocean Tech. 1997, 14, 254-266. [CrossRef]

51. Caires, S.; Sterl, A. 100-year return value estimates for ocean wind speed and significant wave height from the ERA-40 data. J. Clim. 2005, 18, 1032-1048. [CrossRef]

52. Woo, H.J.; Park, K.A.; Byun, D.S.; Lee, J.; Lee, E. Characteristics of the differences between significant wave height at Ieodo Ocean Research Station and satellite altimeter-measured data over a decade (2004 2016). Sea 2018, 23, 1-19. (In Korean with English abstract) 